\title{
A PROPÓSITO DEL HALLAZGO DE UN TRIENTE PROTOVISIGODO EN UXAMA (OSMA, SORIA)
}

\author{
POR \\ CARMEN GARCIA MERINO \\ Departamento de Prehistoria. Arqueologia. Antropologia y Ciencias Historiográficas \\ Facultad de Filosofia y Letras de la Universidad de Valladolid
}

\section{RESUMEN}

El hallazgo en superficie en el casco urbano de la ciudad hispano-romana de Uxama Argaela (Soria) de una moneda de oro de mediados del siglo vi, acuñación de un monarea visigodo bajo el nombre del emperador bizantino Justiniano I. es un nuevo testimonio material que se anade a los todavia escasos documentos sobre la continuidad de la vida de este destacado núcleo en el tránsito a la Edad Media.

\section{SUMMARY}

A gold coin, found within the urban area of the Hispanoroman town of Uxama Argaela (Soria), and dated in the middle of the VI century A.D. is studied. Coined by an Visigothic monarch on behalf of the Bizantinian emperor Justinian I, it makes a new material element which adds to the rather scarce documental evidence preserved there from the transition period to the Medieval Age.

El interés de la pieza que presentamos no se encuentra tanto en su valor numismático como en el hecho de haber sido recogida en superficie en el propio núcleo urbano de Uxama. En efecto, si es bien conocida la relativa abundancia de trientes de esa época, procedentes en su mayoria de tesorillos, salvo contadas excepciones no se puede decir lo mismo de su hallazgo en relación con yacimientos arqueológicos de tipo urbano, y menos aún en la Meseta Norte. Por otra parte, aunque es sabido que Uxama, situada en zona de asentamiento visigodo, tuvo relieve en la etapa hispanovisigótica por albergar una sede episcopal al menos desde el siglo VII, apenas hay manifestaciones materiales de su vida en esos dos siglos y medio. Algunos enterramientos aparecidos fortuitamente en una obra de construcción a principios de los cincuenta (Reinhart, 1945a, fig. 4,d y fig. 7,a, - Ortego, 1955, pp. 235-237) y algún reci- piente cerámico aislado en un depósito de saqueo oculto entre las ruinas de una casa del siglo III (Garcia Merino, 1994), así como una patena litúrgica de bronce, adquirida por el Museo Numantino (Argente $y$ Garcia Merino, 1993, pp. 21-23 y fig. VI), es lo único de que se tiene noticia. A ello hay que añadir el hallazgo de un triente de Suintila en el territorium de la ciudad, en Sotos del Burgo (Mateu Llopis, 1953, p. 94, $n^{\circ} 632$ ). En otro orden de cosas está la constancia de un "episcopus oxomensis» en el III Concilio de Toledo y la pervivencia de la sede episcopal hasta hoy. Esa capitalidad religiosa que, contra lo que podia preverse, no recayó en Clunia, capital administrativa desde hacía varios siglos, parece testimoniar indudablemente un papel destacado para Uxama en esa época. Sin embargo, los materiales arqueológicos con esa cronología son sumamente escasos.

En las excavaciones realizadas en el interior del cinturón defensivo tardo-imperial de la ciudad, bien es cierto que contadas, sólo se han documentado niveles antiguos, anteriores a mediados del siglo III (Garcia Merino, 1991), debido, en nuestra opinión a que los posteriores fueron arrasados por la preparación del terreno para cultivo en la Alta Edad Media. Si en un principio la ausencia de niveles de ocupación bajo-imperiales parecía deberse a un abandono de la ciudad alta en favor de la zona llana (inmediaciones del actual Osma) a finales del Imperio, el abundante material cerámico tardio, asociado con restos constructivos (Garcia Merino, 1989, p. 95. Saquero, Carretero y Guerrero, 1990, pp. 585-598), recogido en el complejo de cisternas de planta semicircular de la cumbre O (excavaciones de 1988) nos llevó a modificar esa opinión. Creemos, por tanto que la falta de niveles de cronología avanzada en las excava- 
ciones de la fona central del casco urbano no se debe interpretar necesariamente como una inexistencia de los mismos. El hallazgo de este material con cronologia del siglo $\mathrm{y}$ parece corroborar tal aserto.

Hace unos años tras una copiosa lluvia que arrastró diferentes materiales arqueológicos del yacimiento. un vecino de Osma recogió la pieza que nos ocupa en el sector SE del L.lano de la Atalaya, junto a unos restos de muros. Se trata de un tremissis o triente protovisigodo de $17 \mathrm{~mm}$ de diametro, 1,32 grs de peso y ejes a las 12 h. El oro es casi puro: $89,96 \%$ y la densidad de $13,12 \mathrm{gr} / \mathrm{cm}^{1}$, siendo la del oro puro de $19 \cdot 3 \mathrm{gr} / \mathrm{cm}^{2}$.

El flan es aplastado y la gráfila se encuentra casi borrada. El estado de conservación se puede considerar regular pues tiene el borde doblado en algunos puntos y el desgaste de la pieza evidencia un periodo de uso no demasiado largo. El trazado de las letras no es todavia cuneiforme y los rasgos paleográficos resultan acordes con la grafia visigótica monetal (G. Miles, 1952, pp. 146-149): la V con una de las hastas doblada en curva, la I con los extremos doblados también, la T con el brazo más ancho en los extremos, la R con la cola muy corta que arranca del hasta vertical, más abajo del ojo, la $\mathrm{N}$ normal y retrógrada $\mathrm{y}$, sobre todo. la $\mathrm{S}$ que presenta dos trazados uno de los cuales, caracteristico de las leyendas visigóticas sobre monedas, es retrógrado y de mayor tamaño que el resto de las letras. Las leyendas tienen incorrecciones, tipicas ya de las acuñaciones próximas al reinado de Leovigildo.

Anverso: Busto del emperador a la derecha con cruz en el pecho y tocado con diadema con infulas. Paludamentum esquemático con silueta de trapecio, bordeado de doble linea de cuenta. El perfil, muy sumario, es de trazos gruesos con el ojo de frente. Sobre el rostro, correspondiendo aproximadamente a la posición de la oreja derecha, parece verse una $\mathrm{S}$, quizá representación de ésta. La leyenda, en dos mitades a ambos lados del busto y desarrollada de abajo a la izquierda hacia abajo a la derecha, es: $\mathrm{C}$ (retroversa)N (retroversa) IVSTI[NI] ANVS PFAVC. Parece una simple reproducción imitativa de los titulos y del nombre del emperador bizantino: D(ominus N(oster) Iustinianus P(ius) A(ugustus). En la repetición de una leyenda como un elemento decorativo el resultado es que la $\mathrm{D}$, retrógrada se convierte en $C$, pegada a un lateral del busto y en posición simétrica con la C(por G) de Aug(ustus) como hizo notar P. Beltrán a propósito de algunas de las piezas del tesorillo de Zorita de los Canes (Beltrán, 1953, p. 42). En cuanto a la parte central del nombre, no está claro si la $\mathrm{N}$ y la l están borrosas por el deterioro o si nunca se escribieron.
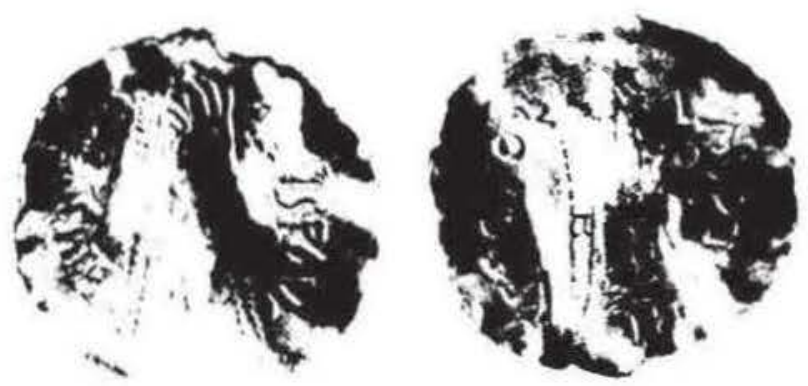

Figura 1. Triente protovisigodo hallado en el casco urbano de Uxama trgaela (Soria), Diametro real de la pieza: $17 \mathrm{~mm}$.

Reverso: Victoria a la derecha con palma y corona. La cabeza es una estrella de seis puntas y el brazo izquierdo se dobla en ángulo recto. Leyenda: VICTOR AAVSTOI. En el exergo ONO y la linea del exergo ligada a las letras de los extremos. El tipo, derivado como se sabe, del bizantino, aunque dificilmente identificable por su tosquedad, no es todavia insectomorfo. Sin llegar a ser la barbarizada Victoria de las series posteriores a Leovigildo. prefigura ya sus rasgos: alas esquemáticas, torpe paso y cuño descuidado de forma que el tipo es casi irreconocible a la par que la leyenda, ortográficamente incorrecta, remeda Victor $[\mathrm{i}] \mathrm{a} \mathrm{Au}[\mathrm{g}]$ ustor(um).

En el anverso aparece el busto de Justiniano, según el texto que dentro de las series de estas caracteristicas mantiene, aún con una grafia peculiar, la estructura de las leyendas romanas en la buscada imitación de los tipos imperiales que precede en las acunaciones visigóticas al establecimiento de tipos propios a partir de los primeros años del reinado de Leovigildo. La corrupción de las leyendas puede ser fruto, bien de la deformación deliberada, bien de la copia sin comprensión del modelo, como también ocurre en el código de la ceca, en origen CONOB. Ambas hipótesis no son nuevas. El efecto que causan es el uso del texto como elemento casi ornamental, independientemente de su significado por lo cual el que no sea ortográficamente correcto o. incluso, como suceḍerá algo más tarde, que la lectura sea incoherente no importa; lo que se busca es la aproximación métrica y morfológica, no la imitación o falsificación puntual.

Es un triente, acuñado por uno de los monarcas anteriores a Leovigildo, de las series llamadas protovisigodas, emitidas bajo el nombre de los emperadores bizantinos y derivadas de tipos romanos en una ceca seguramente hispana. Habria que encuadrarla en el periodo de Justiniano (527-560) que abarca los reinados de Teudis, Teudiselo, Agila y 
Atanagildo. Y si seguimos la opinion de Beltrán (Beltrain. 1953. p. 42) el hecho de que la cruz no penda de dos cadenitas nos llevaria a considerarla anterior a Atanagildo, es decir, anterior a 554. No hemos podido encontrar un paralelo exacto en la bibliografia disponible acerca de esas emisiones. Por el tipo de leyenda del anverso. de seguir la clasificación de Reinhart, se podria asimilar a las del grupo B, con leyendas relativamente correctas, que este autor distingue entre los trientes acuñados entre 527 y Leovigildo y atribuye, especialmente, a la ceca de Sevilla (Reinhart, 1945b, pp. 227-228). El tipo de pectoral corresponde al 7 de Gil Farrés que según este autor tiene una cronología coincidente con el periodo citado más arriba (Gil Farrés, 1976. pp. 152153 y fig. $X I X, n^{\circ} 7$ ). Es en el tesorillo de trientes hallado en el baptisterio de la basilica de Recópolis donde parece haber una similitud mayor. Podria ser una variante de los que Cabré (Cabré, 1953, pp. 22 23 y Lám. IX 13-26) clasifica en el reinado de Theudis (531-548). No es de extrañar esa falta de réplica, dada la abundancia y variedad de estas acunaciones. Lo que está claro es que se trata de una de las más tempranas series de este tipo; por la relativamente poca importancia de los "errores" en las leyendas y por la ausencia de cadenitas en el pectoral, así como por el tipo del reverso se podria pensar en fechas anteriores al reinado de Atanagildo. Asimismo la relativamente reducida incorrección textual parece apuntar hacia una ceca del Sur; quizá Sevilla, sede real con Teudis y ceca y centro cultural antes y después de él, si bien es más lógico que fuese Toledo la eeca difusora de monetario para esta zona, antes incluso de ser la capital del reino. En cualquier caso lo que está claro es que corresponde al conjunto monetal protovisigodo en que los reyes aún no ponian su nombre en el anverso y la gran pureza del metal, el pequeño módulo y el peso, apuntan también a una época temprana, pues entre estas acuñaciones godas que imitan las piezas imperiales en los años de crisis, las más recientes presentan un envilecimiento del peso y la ley (Tomasini, 1964). De acuerdo con ello este triente podria ser anterior a la captura del tesoro real por los cordobeses en 550, lo que incide nuevamente en el reinado de Atanagildo como fecha ante quem ya que, además, su peso no se ajusta a los de las series recogidas en Recópolis, en su mayoría de Leovigildo o contemporáneas de sus primeros años (Beltrán, 1953, 51).

Finalmente hemos de señalar el hecho interesante, de cara a futuras excavaciones en el yacimiento, de que este divisor del solidus apareció en un sector del E. de la ciudad, no alejado del Foro, donde, en fotografia aérea, se perciben con extraordinaria ni- tides una serie de alineaciones en sentido E-O que parecen evidenciar una trama urbana, de estructuras constructivas aun con bastante volumen. Tal ve' quepa la esperanza de que en esa área los niveles arqueológicos mas recientes permanezan intactos todavia. No se puede deseartar que, ya en la quinta centuria, por una serie de causas: epidemias, malas cosechas, catastrofes naturales, etc. que incidieron en la demografia y en el nivel de riqueza general, la poblacion se asentase preferiblemente en el llano. al pie del castro quizá en torno a una iglesia martirial o con reliquias importadas. Sin embargo, hay que tener en cuenta también la posibilidad, timidamente sugerida por este hallazgo, de que el habitat del viejo núcleo siguiese en el mismo emplazamiento, al menos antes de la figura unificadora de Leovigildo $y$ su conversión al catolicismo.

\section{AGIRADECIMIENTOS}

Agradecemos a $\mathrm{M}^{\text {a }}$ Soledad Parrado Cuesta, autora de los análisis, metalográfico y densométrico del triente, su generosa colaboración. También queremos hacer constar nuestra gratitud a I. I. M. por la gentileza mostrada al permitirnos dar a conocer la pieza.

\section{REFERENCIAS BIBLIOGRÁFICAS}

Arcilnti, J. L., y GARCiA Mirino C. (1993): Bronces hispanorromanos del Museo Numantino. procedentes de Uxama. Bronces y religion romana. (Actas del XI Congreso Internacional, Madrid, 1991), pp. 13-32.

Beltrin, P. (1945) «Monedas de Leovigildo en el tesorillo de Zorita de los Canes (año 1945). N. H. II, pp. 19-53.

CABRÉ, J. (1946): «El tesorillo visigodo de trientes en las excavaciones del Plan Nacional de 1944 45 en Zorita de los Canes (Guadalajara)". Informes y Memorias, $\mathrm{n}^{\circ} 10$.

Garci^ Mtrino, C. (1989): "Uxama. El yacimiento y su historian. Catálogo de la exposición Diez años de Arqueologia soriana ( 1978-1988). Soria, 1989 , pp. 87-96.

GArci Mi:rino, C. (1991): "La casa urbana en Uxama Argaelan. La casa urhana hispanorromana. Actas del Symposium (Zaragoza, 1989). Zaragoza, 1993, pp. 233-259.

Garcin Mirino, C. (1940): UXAMA I. Campañas de 1976 y 78 . La casa de la cantera, la casa del sectile y el Tambor. Madrid, 1994.

Gil. FArrés, O.(1976): Historia de la moneda española. Madrid, 1976. 
MAnt Liopss. F. (1951): "Hallazgos monetarios" VIII. $\mathrm{NH} 22$. p. $94 . \mathrm{n}^{\circ} 632$.

Mus. G.: (1952) The coinage of the Visigothics of Spain from Leorigild to Achila. Nueva York.

Ortheic) Friss, T. (1955): "Noticiario. Osma». N.A.H. II. Cuad. 1-3. (1953).

RIINHART. W. (1945a): "Nuevas aportaciones a la numismática visigodan. AEsp.A. 18, pp. 212 2.35.

RHINHART, W. (1945b): «Sobre el asentamiento de los visigodos en la Peninsulan. AEsp.4. 59, pp. 124-139.

SAQtiRo, B., CARRITHRo, S., y (ithrRtR(), J. (1992): "Terra sigillata hispánica tardia procedente de Uxaman. Actas del Segundo Simposium de Arqueologia soriana (Soria, 1990). Soria, pp. 885 898.

TomAsINI. J. (1964): «The barbaric tremissis in Spain and Southern France: Anastasius to Leovigild». Numismatic Notes and Monographs, 152. Nueva York. 